\title{
La inscripción SEG 34.1532 y la de Alejandría en Egipto ptolemaico
}

Recibido: 03/09/2018. Aceptado: 17/12/2018

\begin{abstract}
Resumen
En este artículo nos proponemos analizar la terminología registrada en SEG 34.1532, especialmente las referencias que aluden a la existencia de la $\gamma \varepsilon @ o v \sigma i ́ \alpha$ en Egipto ptolemaico y sus funciones administrativas vinculadas con el gimnasio de Alejandría. Intentaremos traducir SEG 34.1532 y rastrear el término $\gamma \varepsilon$ @ov $\sigma i ́ \alpha$ y el vocabulario relacionado con este consejo, y examinar los datos sobre su existencia y potestad en Egipto ptolemaico, además de su conexión con el gimnasio alejandrino. La lectura de esta inscripción y su contextualización histórica y social nos permitirán discutir también acerca de los términos técnicos ligados con la $\gamma \varepsilon \varrho o v \sigma i ́ \alpha$ en el período ptolemaico tardío.
\end{abstract}

PALABRAS CLAVE: SEG 34.1532, traducción, gerousía, gimnasio, Egipto ptolemaico.

The inscription SEG 34.1532 and the Alexandrian gerousia in Ptolemaic Egypt

\begin{abstract}
In this article we propose to analyze the terminology registered in SEG 34.1532, especially the references that allude to the existence of the $\gamma \varepsilon Q 0 v \sigma i \alpha$ in Ptolemaic Egypt and its administrative functions linked to the gymnasium of Alexandria. We will try to translate SEG 34.1532 and trace the term $\gamma \varepsilon$ Qov oí $\alpha$ and the vocabulary related to this council, and to examine the data about its existence and power in Ptolemaic Egypt, in addition to its connection with the Alexandrian gymnasium. The reading of this inscription and its historical and social contextualization will allow us to also discuss about the technical terms associated with the $\gamma \varepsilon$ govoí $\alpha$ in the late Ptolemaic period.
\end{abstract}




\section{Introducción}

SEG 34, 1532 forma parte de la colección de epigrafías griegas del Museo Greco-romano de Alejandría. Es una estela de mármol blanco, que tiene una altura de $0,61 \mathrm{~cm}$ y un largo de $0,23 / 24 \mathrm{~cm}^{.}{ }^{1}$ La parte superior y derecha ${ }^{2}$ está incompleta, mientras que la izquierda está mutilada en el sector de arriba pero conserva un texto de 32 líneas (11.), de las cuales la l.19 tiene una proyección inicial que excede el margen de la piedra. Está datada en la época ptolemaica, aunque el estado fragmentario de la inscripción ha tornado difícil la tarea paleográfica destinada a determinar el lugar del que procede y el período histórico en el que fue escrita.

Los primeros editores de la inscripción fueron Botti, quien publicó este fragmento en la Rivista Egiziana IV (1894:344), ${ }^{3}$ y Milne (Strack), cuya edición fue impresa en el Archiv für Papyrusforschung 3 (1906:138). Ninguno se arriesgó a situar o datar el texto en una región o tiempo específico. Más tarde Breccia volvió sobre la edición de Botti y Milne (Strack), restauró nuevamente la inscripción y le asignó el № 162 en su Catalogue Général des Antiquités Égyptiennes du Musée d'Alexandrie. Iscrizioni Greche e Latine (1911:93-94). A pesar de las dudas que demuestra en precisar su ubicación y fecha de escritura, asegura que la misma fue "acquistata nel negozio Stamati Vinga" (1911:93) y luego pasó a integrar la colección del Museo Grecorromano de Alejandría; propone localizar la epigrafía en esta ciudad egipcia y fecharla entre los siglos II-I a.C. La misma lectura es aceptada por Meyer (1913:740), Fraser (1972: 177, nota 16) y Bingen (1984:239-243). En su reseña de la obra de Iscrizioni Greche e Latine, Meyer repara alguna de las palabras dejadas incompletas por Breccia y sugiere datar la inscripción en el siglo II del "späteren Ptolemäerzeit" (1913:740). Fraser, por su parte, afirma que la inscripción es la parte izquierda de una piedra del período "late Ptolemaic" (1972:177, n.16); si bien sugiere que Alejandría podría ser su lugar de origen, defiende que la inscripción es de procedencia desconocida. Bingen (1984:239-243) se hace eco de la interpretación de Fraser. Basado en la edición de Breccia y en las reparaciones de Meyer, reedita la inscripción y agrega algunas enmiendas. Pese a que no se compromete a precisar la fecha de escritura del texto, estima que, a juzgar por la información que contiene, debe ser datado en el siglo II a.C. ${ }^{4}$ y, al igual que Fraser, vacila en el momento de fijar un lugar de procedencia. A partir de los datos sobre el traslado de la piedra desde una colección privada de Alejandría hacia el Museo Grecorromano de esa ciudad aportados por Breccia, Bingen no descarta un origen alejandrino de la inscripción. Sin embargo, piensa que Alejandría, como otros puertos del Mediterráneo, albergaba gran cantidad de piedras errantes, por lo que plantea la posibilidad de que el documento provenga de la costa de Asia Menor o de las islas del Egeo (1984:241). Esta tesis es mantenida por Pleket y Stroud, quienes reeditan la restauración de Bingen, publican la inscripción en

1 Sobre los datos relacionados con la conservación de la inscripción, cfr. Milne; Strack (1906:138); Breccia (1911:93); Bingen (1984:239-240).

2 Cfr. Breccia (1911: 63); Bingen (1984:239).

3 No hemos podido revisar esta edición a causa de la inexistencia del archivo en los lugares consultados. Citamos los datos dados a conocer por Milne; Strack (1906:138), Breccia (1911:94) y Bingen (1984:240).

4 Cfr. Launey (1949-1940); Delorme (1960). 
el volumen 34 del Supplementum Epigraphicum Graecum (SEG 1987:418-419) y le asignan el número 1532. Sintetizan la información dada a conocer por los editores anteriores y ratifican que originalmente la piedra formó parte de una colección privada alejandrina (1987:419) ${ }^{5}$ que, entre fines del siglo XIX y principios del XX, fue adquirida por el Museo Greco-romano de Alejandría, donde reside en la actualidad. Consideran que su procedencia fuera de Egipto, más precisamente de Asia Menor, "is not excluded" (1987:419), y datan la piedra en el siglo II a.C.

A pesar del esfuerzo de los estudiosos por fijar la procedencia de la epigrafía y su época de emisión, sus exámenes críticos se fundan sobre elementos gráficos de la escritura de un documento que presenta particularidades contradictorias derivadas de su estado incompleto. Si bien la mayoría de los investigadores coincide en localizar la inscripción en Alejandría y fechar su aparición en el período ptolemaico tardío, la pobreza relativa del contexto paleográfico no permite garantizar ninguna certeza. No obstante, el texto conservado sigue siendo uno de los testimonios más antiguos sobre la actividad de la $\gamma \varepsilon \varrho o v \sigma i ́ \alpha$ en Egipto ptolemaico. En este sentido, mediante la traducción e interpretación de la estructura y contenido de la inscripción SEG 34.1532 intentaremos ampliar nuestro conocimiento acerca de la existencia de la $\gamma \varepsilon \varrho o v \sigma i ́ \alpha$ en el siglo II a.C., a la vez que explicar la información transmitida por tan controvertido documento, en especial la vinculación de la $\gamma \varepsilon \varrho o v \sigma i ́ \alpha$ con el gimnasio de Alejandría. Con este propósito, nos proponemos rastrear el término $\gamma \varepsilon \varrho 0 v \sigma i ́ \alpha$ y el vocabulario relacionado con el consejo en la inscripción griega antes mencionada para examinar los datos acerca de su existencia en Egipto ptolemaico y su conexión con otras instituciones como el gimnasio alejandrino. La lectura de esta inscripción, además de la contextualización histórica y social, nos permitirá discutir también sobre el entramado de términos técnicos que proporcionan información sobre la función de la $\gamma \varepsilon \varrho o v \sigma i ́ \alpha$ en el período ptolemaico tardío y su potestad administrativa.

\section{La traducción y estructura de la inscripción}

La tarea de expresar en una lengua lo escrito primariamente en otra distinta no es sencilla, más aún cuando no existen traducciones modernas que asisten en el trabajo de interpretar aquello enunciado en el texto original. ${ }^{6}$ Ante esta dificultad, la traducción del documento griego ${ }^{7}$ grabado en SEG 34.1532 intenta reproducir en castellano de la manera más literal posible lo formulado en griego y mantener la disposición del texto editado por Bingen (1984:240). Su edición, de la misma manera que la restauración de Breccia (1911:93-94), está determinada por el texto de la parte izquierda del documento, cuya sección inicial está perdida. Esta mutilación y el estado fragmentario del texto preservado parecen haber oscurecido la comprensión de la temática completa de la inscripción; sin embargo, la restauración de la sección izquierda llevada a cabo por Bingen aporta nuevos datos léxicos que pueden ser descifrados

5 Cfr. Fraser (1972:177, n. 16).

6 La inscripción SEG 34.1532 es por primera vez traducida a una lengua moderna en el presente estudio.

7 Hemos agregado entre '[]' algunas palabras que, aunque no presentes en el texto griego, precisan el sentido de ciertas expresiones confusas en el documento. También hemos colocado '/' para diferenciar las distintas acepciones de un mismo caso gramatical o frase. Por lo demás, nuestra traducción presenta notas al pie que apuntan a reducir la distancia entre el lector actual y el documento. 
y contextualizados con cierto grado de satisfacción, como se observa en la traducción que proponemos a continuación:

\begin{tabular}{|c|c|c|}
\hline 1 & 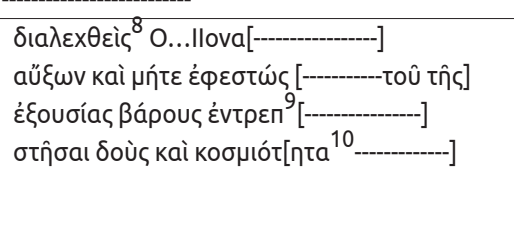 & $\begin{array}{l}\text {...que ha sido expresado... } \\
\text { también aumentando }{ }^{11} \text { sin que se interrumpa } \\
\qquad[\ldots \text { de la/del } \\
\text { carga/peso de la magistratura }{ }^{12} \ldots \\
\text { poniendo a votación }{ }^{13} \text { que se levante [una } \\
\quad \text { [piedra] }{ }^{14} \text { y el destacadísimo buen orden }{ }^{15} \text {.. }\end{array}$ \\
\hline 5 & 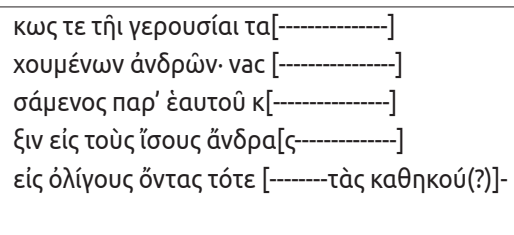 & $\begin{array}{l}\text {... por la gerousía... } \\
\text { de hombres conspicuos ... } \\
\ldots \text { en su propio... } \\
\ldots \text { a los hombres iguales ... } \\
\text { estando en unos pocos }{ }^{16} \text { en este caso ... las que } \\
\quad \text { [corresponden(i?) }\end{array}$ \\
\hline
\end{tabular}

8 Cfr. Aeschin.1.17-18; D.43.59.

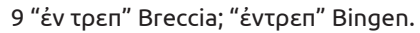

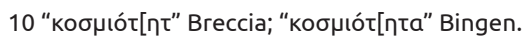

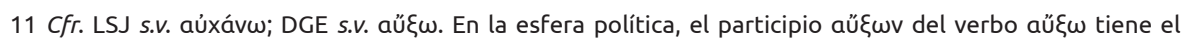
sentido literal de 'hacer aumentar las fuerzas o el poder', 'hacer prosperar'. Cfr. Thgn.823; Hdt.8.30; 9.31; Th.6.40; X.HG 7.1.24; D.3. 26. También tiene el sentido de 'engrandecer', 'enaltecer', 'proporcionar gloria' a

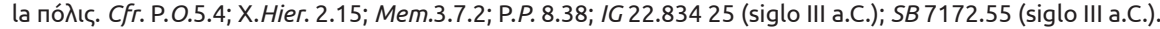

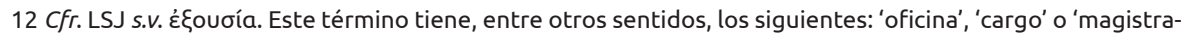
tura' (cfr. Pl. Alc.1.135b; Arist.EN1095b21; Rh.1384a1; LXX.Da. 3.2); 'cuerpo de magistrados' (cfr. D.H.11.32); 'autoridades' (cfr. Ev.Luc.12.11; Plu.Phil. 17), que en ocasiones adquiere el valor de un título honorífico (cfr. P.Oxy.1103, siglo IV d.C.).

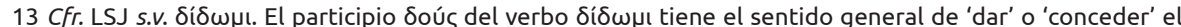
derecho para realizar una acción (cfr. D.7.26.1). Pero también es usado en el ámbito jurídico y político para las ideas de 'prestar' juramento (cfr. Is.9.24, D.39.3; Arist.Rh.1377a8), 'poner' a votación (cfr. D.21.87), 'proponer' una resolución (cfr. D.24.13), 'presentar' un decreto (cfr. Aeschin.2.13).

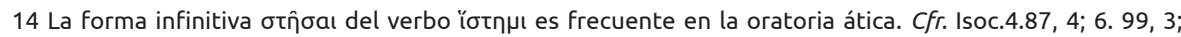
And.22.3; D.19.330.3; 26.23.10; 31.13.9; 41.16. 3; 59.105.8; Aeschin.183, 6. En la mayoría de estos casos, бtก̂бaı refiere a la erección de una estatua o piedra propuesta en el ámbito de una asamblea o a partir de una decisión parlamentaria. Un uso similar del término se observa en las fuentes de los historiadores. $C F r$. Hrd.2.121; 4.15; D.H.2.74.

15 Cfr. Lys.26.3; D.59.80.7; Ph.Flacc. 99.

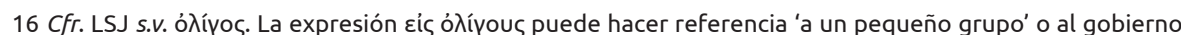

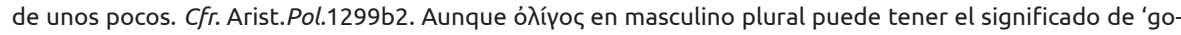
bierno oligárquico'.

17 Cfr. LSJ s.V. kaӨńkw. El verbo puede aludir a todo aquello que es legalmente debido o conveniente cuando corresponde en virtud de las leyes. CFr. D.19.185. Pero, junto con el sustantivo üpa, pude referir al período de tiempo previsto para la convocatoria a una asamblea, la fijación de una sentencia, la ejecución de una acción resuelta de antemano, etc. Cfr. X.HG 4.7.2; P.Rev. 41.14 (siglo III a.C.). 


\begin{tabular}{|c|c|c|}
\hline 10 & 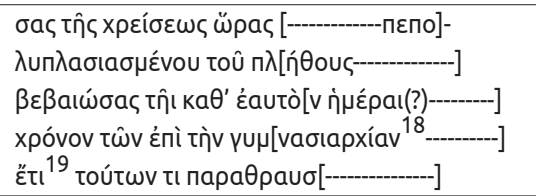 & $\begin{array}{l}\text { al tiempo necesario }^{20} \ldots \\
\text { cuando incrementa }{ }^{21} \text { el número ... } \\
\text { en el plazo establecido }{ }^{22} \ldots \\
\text { el tiempo conforme a la gimnasiarquía }{ }^{23} \ldots \\
\text { aun [si] algo de esto se infringe } ?^{24} \ldots\end{array}$ \\
\hline 15 & 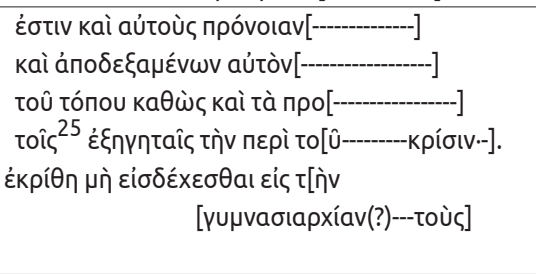 & $\begin{array}{l}\text { los mismos que también tienen el propósito / } \\
\text { [previsión }{ }^{26} \ldots \\
\begin{array}{l}\text { y aprobándolo } \ldots \\
\text { de allí mismo según }{ }^{27} \ldots\end{array} \\
\text { [a la sentencia }{ }^{28} \text { sobre ... } \\
\text { Ha decidido no aceptar en la gimnasiarquía(¿?)... } \\
\text { [a los }\end{array}$ \\
\hline 20 & 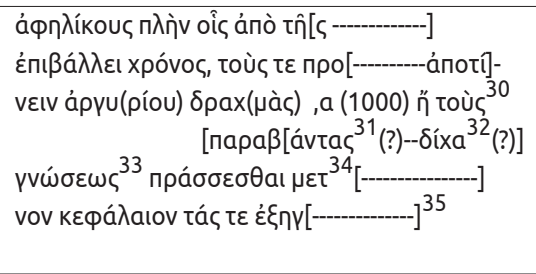 & $\begin{array}{l}\text { menores [ante la ley] }{ }^{36} \text { excepto aquellos para } \\
\text { [quienes... } \\
\text { impone una edad..., a los... } \\
\text { pagar } 1000 \text { dracmas de plata o a los que se } \\
\text { [apartan [de la ley](¿?)... contra (¿?) } \\
\text { la instrucción judicial que exige ... } \\
\text {...cabeza / principal a los ... }\end{array}$ \\
\hline
\end{tabular}

18 "vuv" Breccia; "vup[vacıapxíav" Meyer, enmienda seguida por Bingen.

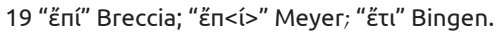

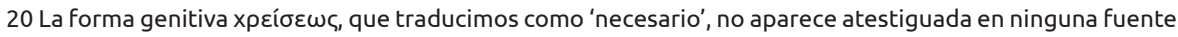
antigua, siendo SEG 34.1532 la primera que la registra.

$21 \mathrm{El} \mathrm{forma} \mathrm{"п \varepsilon по \lambda uп \lambda a \sigma ıa \sigma \mu \varepsilon ́vou"} \mathrm{es} \mathrm{un} \mathrm{participio} \mathrm{del} \mathrm{verbo} \mathrm{по \lambda uп \lambda a \sigma ıáł \omega ,} \mathrm{cuyo} \mathrm{uso} \mathrm{es} \mathrm{poco} \mathrm{común} \mathrm{en}$ la Antigüedad, siendo esta inscripción uno de los primeros documentos que da noticias sobre su empleo en época helenística. CFr. LXX.De.8.1, donde la forma verbal aparece en un ámbito prescriptivo.

22 Cfr. LSJ; DGE s.v. ßعßaı́w. Tiene el significado de 'consolidar' o 'asegurar' en beneficio de alguien y hasta de 'sancionar', 'confirmar' o 'garantizar' leyes. Cfr. Th.1.122; Pl. Cri.53b; X.An.7.6.17; Lys.6.29; Is.9.34. El verbo surge en papiros, frecuentemente en cláusulas legales. Cfr. BGU 1267.17 (siglo III a.C.); UPZ 177.36 (siglo II a.C.); BGU 1119.47 (siglo I a.C.); PMil.Vogl.220.29 (siglo II d.C.).

23 Cfr. DGE s.v. yujvaoiapxía. Esta acepción hace referencia 1) al cargo de gimnasiarco como una liturgia (cfr. Isoc.16.35; Plu.Nic.3; también D.20.125; X.Ath.1.13; Oec.2.6; IG 12(2).82.23) y 2) al cargo de gimnasiarco del gimnasio, como institución de educación de efebos (cfr. Pl.Ax.367a; Arist.Pol.1323a1). También a la gimnasiarquía que en Roma y en Egipto romano era un cargo de prestigio en las metrópolis (cfr. IG5(1).531.8 (siglo II d.C.); IEphesos 2925; PAmh.70.3 (siglo II d.C.). El cargo podía heredarse o comprarse. Cfr. SB 13032 (siglo II d.C.).

24 La palabra incompleta "параӨраuб[------------]" posiblemente sea una forma del verbo nараӨраúw, cuyo uso es poco frecuente en las fuentes griegas que datan entre los siglos VIII y I a.C. Cfr. Dialex.1; Demad.44; también. Pl.Lg.757e.

25 "тої" Breccia; "тoîs" Meyer y Bingen.

26 Cfr. A.Ag.684; S.Tr.823; Aj.536; OT978; Ph.774; El.1015.

27 Para la expresión tónou kaӨúc, que puede ser traducida como 'de allí según', 'de acuerdo con', 'de allí mismo como o según', cfr. J.Vit.319.

28 Este sentido del término kpíøıc, que tiene el significado de 'sentencia', 'decisión' o 'resolución' de un tribunal que concluye un juicio o un proceso (cfr. LSJ s.V. kpíбıc) cobra mayor relevancia a partir de su conexión con el ع́kpí̈n que inicia la l. 19. Cfr. Lys.13.50.

29 Sobre la función del ḱદnүnтńc, cfr. Hrd.1.78; 3.31; Pl.Lg.759c; 828b; 873d; D.47. 68; 71. Sobre la elección de estos funcionarios, cfr. Pl.Lg.759d-e.

30 "toîc" Breccia; "toúc" Meyer y Bingen.

31 "параß" Вrессіа; "параß[ávtac" Meyer у Bingen.

32 "סíxa"es una enmienda de Meyer y Bingen.

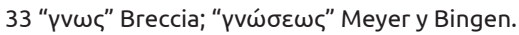

34 "Mعt[a"Breccia; " $\mu \varepsilon \tau$ " Bingen.

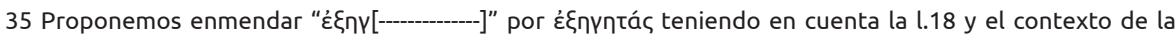
inscripción.

36 Cfr. DGE s.v. áథńגıkoc. Cfr. PSoterichos 26.5 (siglo I d.C.); PMich.538.6 (siglo II d.C.); PMasp.6re.2 (siglo VI 


\begin{tabular}{|c|c|c|}
\hline 25 & 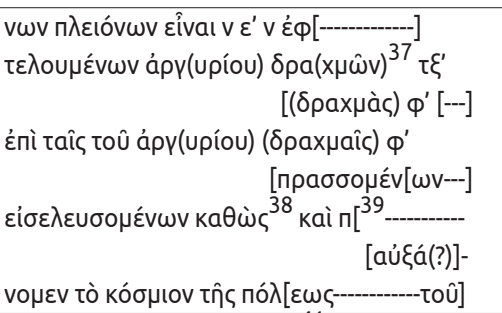 & $\begin{array}{l}\text {...de lo que es superior a cinco... } \\
\text { pagando } 360 \text { dracmas de plata, } 500 \text { dracmas... } \\
\text { exigir sobre } 500 \text { (dracmas) de plata ... } \\
\text { a los que/de las que entrarán/ingresarán }{ }^{40} \text { al } \\
\text { [mismo tiempo que... } \\
\text { aumentamos(¿?) el orden de la ciudad ... del }\end{array}$ \\
\hline 30 & 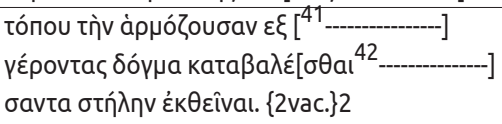 & $\begin{array}{l}\text { lugar que administran }{ }^{43} \ldots \\
\text { decreto que establecen los ancianos ... } \\
\text {... exponer [públicamente] }{ }^{44} \text { la piedra. }\end{array}$ \\
\hline
\end{tabular}

Como se observa en la traducción presentada arriba, la mutilación del texto impide especificar el contenido exacto del documento; no obstante, se pueden identificar tres partes principales: 1 ) la presentación de las autoridades involucradas en la resolución y su función administrativa (1l.1-9), principalmente aquella desempeñada por quienes integran la $\gamma \varepsilon @ o v \sigma i ́ \alpha(1.5)$ o por los funcionarios que son miembros de un grupo selecto (1l.6, 8 y 9), sobre quienes recaería la potestad de presidir y hacer votar a los reunidos (1.4) y el posible motivo general del encuentro $(1.3) ; 2$ ) la actividad jurídica registrada por el documento (ll.10-30), donde se incluye a) la institución pública que estaría siendo intervenida por la actuación de las autoridades presentes, que sería el gimnasio aludido por el texto a través del término $\gamma v \mu\left[v \alpha \sigma \iota \alpha \varrho \chi_{i ́} \alpha\right.$ (1.13), b) los posibles sujetos que son motivo del proceso resolutivo, mencionados por medio del acusativo plural " $\alpha \phi \eta \lambda$ íkous" (1.20) y su vinculación con la $\gamma v \mu[v \alpha \sigma \iota \alpha \varrho \chi i ́ \alpha$ (l.19), y c) la imposición de una sanción pecuniaria o la determinación de la obligación tributaria a cargo de los potenciales contribuyentes (11.21-28); y 3) la ejecución administrativa (11.29-32), que menciona nuevamente a las autoridades que habrían participado en la decisión jurídica, señaladas por el texto con el acusativo plural " $\gamma \varepsilon \dot{0} 00 v \tau \alpha \varsigma$ " (1.31), y concluye con una orden de carácter público (1.32).

Lamentablemente no se puede presentar el contenido completo de la inscripción, no por nuestra arbitraria preferencia, sino porque el estado incompleto del texto requiere una gran contextualización que es imposible exponer aquí en su totalidad. Solo se pueden extraer algunos datos referenciales que

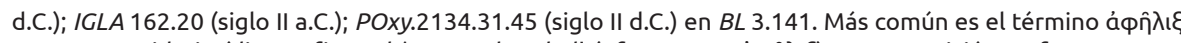
que, en sentido jurídico, refiere al 'menor de edad' (cfr. DGE s.v. áథn̂入ı)), cuya aparición es frecuente en papiros de época tardía. Cfr. PMich.577.3.11 (siglo I d.C.); POxy.3508.34; 3510.8 (siglo I d.C.); 3470.15 (siglo II d.C.); PGrenf.1.47.6 (siglo II d.C.); 1.49 .12 (siglo III d.C.).

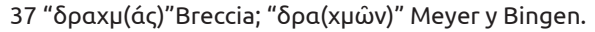

38 каӨ' ш̈ Breccia; каӪ́s Meyer у Bingen.

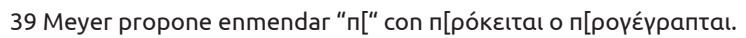

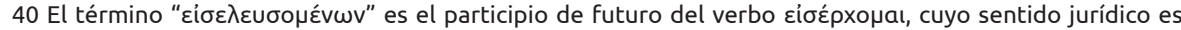

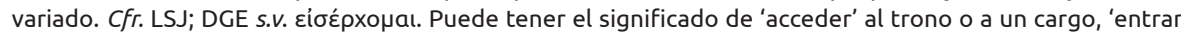
en funciones', 'empezar a desempeñar' (cfr. IG 13.369 .10 y 364.11; 365.26 (siglo V a.C.); Antiph. 6.44; ISestos 1.61 (siglo II a.C.); D.C.41.39.1), o el sentido general de 'entrar en' o 'ingresar' dinero en el arca de la ciudad (cfr. X.Vect.5.12; IG 11(2).161A.122 y 162A.29, ambas del siglo III a.C.).

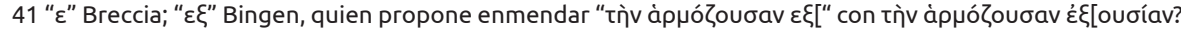
(1984: 242, ก. 14).

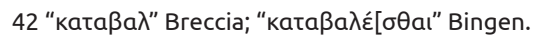

43 Cfr. Yarza s.v. àpuółw.

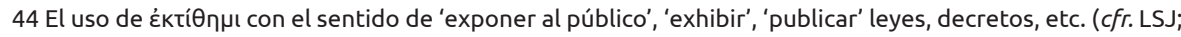

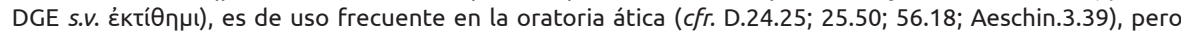
también en los textos de época tardía. Cfr. PPetr.2.13.18b.10 (siglo III a.C.); Plb.31.6.1; Plu.Luc.36. 
permitan lograr una aproximación al tema referido por el texto. Estos datos y el vocabulario específico expuesto en cada línea de la inscripción han dado lugar a distintas interpretaciones que se focalizan fundamentalmente sobre la existencia de la $\gamma \varepsilon \varrho o v \sigma i ́ \alpha$ en Egipto ptolemaico, su poder administrativo y su conexión con una de las instituciones más importantes del período helenístico, el gimnasio. Cada una de estas temáticas será analizada en los apartados siguientes.

\section{La $\gamma \varepsilon \varrho o v \sigma i ́ \alpha$ y su función en la administración ptolemaica}

La primera y la tercera parte de la inscripción anotan los datos relativos a la

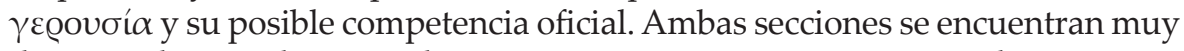
deterioradas; no obstante, algunas expresiones permanecen completas y aportan referencias que permiten probar tanto la presencia del consejo de ancianos y de otros posibles funcionarios implicados en la resolución, como su potestad administrativa, según se advierte en las 1l.1-10 y 28-32 que copiamos abajo:

\begin{tabular}{|c|c|c|}
\hline 1 & 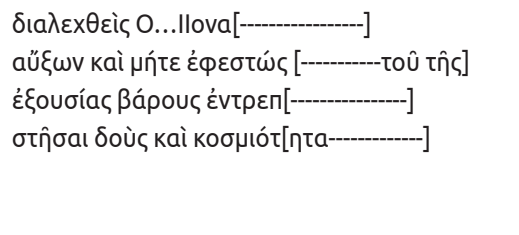 & $\begin{array}{l}\text {...que ha sido expresado... } \\
\text { también aumentando sin que se interrumpa [--- } \\
\text { [de la/del] } \\
\text { carga/peso de la magistratura... } \\
\text { poniendo a votación que se levante [una piedra] } \\
\quad \text { [y el destacadísimo buen orden... }\end{array}$ \\
\hline 5 & 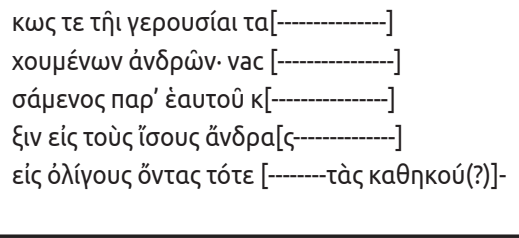 & $\begin{array}{l}\text {... por la gerousía... } \\
\text { de hombres conspicuos ... } \\
\ldots \text { en su propio... } \\
\ldots \text { a los hombres iguales ... } \\
\text { estando en unos pocos en este caso ... las que } \\
\qquad \text { [corresponden(?) }\end{array}$ \\
\hline 29 & 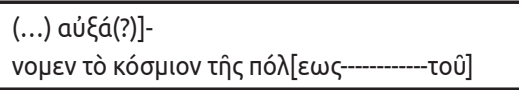 & ... aumentamos el orden de la ciudad ... del \\
\hline 30 & 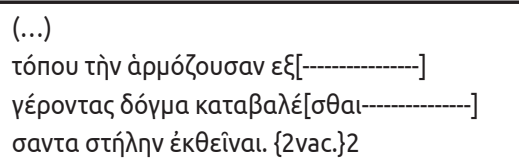 & $\begin{array}{l}\text { lugar que administran ... } \\
\text { decreto que establecen los ancianos ... } \\
\text {... exponer [públicamente] la piedra. }\end{array}$ \\
\hline
\end{tabular}

Si bien las extensas lagunas de estas secciones dejan muchas preguntas abiertas sobre las facultades de los allí señalados, la palabra $\gamma \varepsilon \varrho o v \sigma i ́ \alpha$ se preserva intacta (1.5), de la misma manera que las frases " $\chi 0 u \mu \varepsilon ́ v \omega v$

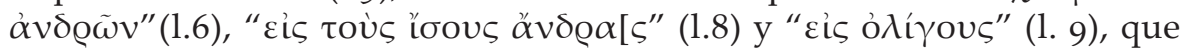
posiblemente remiten a los " $\gamma \varepsilon \dot{0} 0 \nu \tau \alpha \varsigma^{\prime}$ " (1.31) nombrados por la estela en la sección final. El resto de las expresiones está relacionado con la potestad de esos magistrados dentro del ámbito jurídico y administrativo, como el poder para conceder la votación de la erección de una piedra (" $\sigma \tau \tilde{\eta} \sigma \alpha \iota$

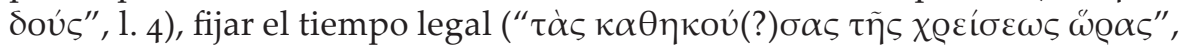

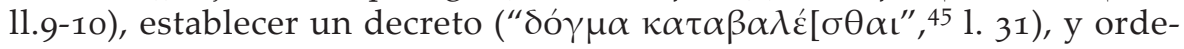

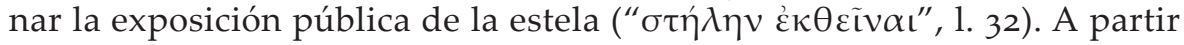
de este vocabulario, Meyer (1913: 739-742) clasifica el texto dentro de la 
categoría "Beschlüsse von Körperschaften und Varia" (p. 739) y sostiene que

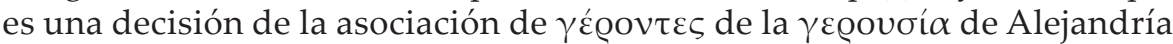
durante el período ptolemaico tardío. El autor no expone otros argumentos que ayuden a entender el fundamento de su interpretación; sin embargo, su clasificación del documento dentro de una categoría jurídica consiguió repercusión en investigadores posteriores como Fraser (1972:177, n.16), quien aceptó la tesis de Meyer y consideró que la inscripción es la porción izquierda de un decreto que contiene noticias precisas sobre la $\gamma \varepsilon \varrho o v \sigma i ́ \alpha$

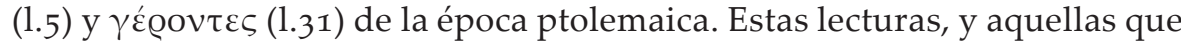
sitúan la epigrafía en Alejandría del siglo II a.C. expuestas más arriba, conducen a sugerir que, en el estado de la documentación actual, SEG 34.1532 es la primera evidencia histórica ${ }^{46}$ del funcionamiento de la $\gamma \varepsilon$ Qov $\sigma i ́ \alpha$ en la ciudad egipcia durante el período ptolemaico, 47 cuya función oficial solo puede ser deducida de los escasos datos grabados en la piedra.

En efecto, la información transmitida por la estela muestra que el consejo habría constituido un órgano jurídico y administrativo, formado por ancianos investidos de prerrogativas especiales, de ahí las afirmaciones " $\chi 0 u \mu \varepsilon ́ v \omega v$

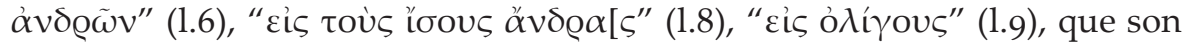

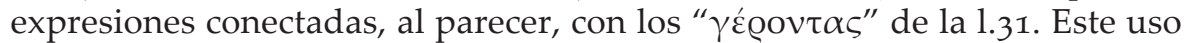
plural del adjetivo $\gamma \varepsilon \dot{Q} \varrho \omega \nu$ designa a los miembros de un cuerpo de ancia-

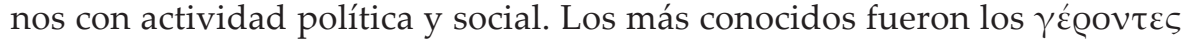
pertenecientes a la $\gamma \varepsilon$ Qovoía de Esparta, que fue una de las asociaciones de ancianos más conocidas de la Antigüedad griega; $4^{8}$ formaba parte de la organización del gimnasio de la ciudad y funcionaba como un consejo municipal compuesto por dos reyes y veintiocho miembros elegidos entre los principales ciudadanos mayores de sesenta años; integraban un órgano de gobierno que atendía juicios en materia criminal y ejercía gran poder sobre todo el Estado. ${ }^{49}$ En época ptolemaica, los $\gamma \varepsilon \dot{Q} 00 \nu \tau \varepsilon \varsigma$ también formaban parte de un cuerpo colegiado en función, como lo confirman tanto la presencia del término en la l.31 de la inscripción SGE 34. 1532 como el resto del vocabulario posiblemente referido a los miembros de la misma institución. Esta información, y la carencia de otra documentación probatoria, llevó a San Nicolò ([11913] 1972:41) a reconocer que en Alejandría ptolemaica no

\footnotetext{
46 Otro testimonio sobre su presencia en Egipto ptolemaico es literario y pertenece a la Carta de Aristeas, que relata las circunstancias de una embajada que el rey Ptolomeo II Filadelfo (285-246 a.C.) envió al sumo sacerdote de Jerusalén con el fin de conseguir un ejemplar de la ley judía para su traducción al griego, y traer a los que cumplirían con esa labor. La Carta refiere que la traducción completa de la Torá se presentó

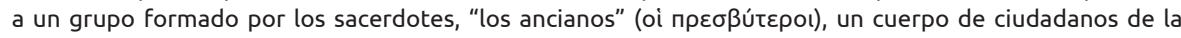

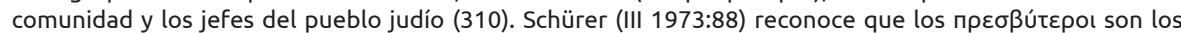

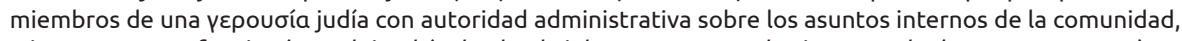
e interpreta que funcionó en Alejandría desde el siglo III a.C. Pero Tchericover; Fuks (CPJ। 1957:9, n.24) no aceptan esta interpretación. Defienden, en cambio, que un consejo de ancianos de la comunidad judía en Alejandría ptolemaica "is not suported by any literary evidence".
}

47 Esta tesis solo podría ser confirmada por la inscripción SB 1.2100 datada en el siglo I a.C. y ubicada en

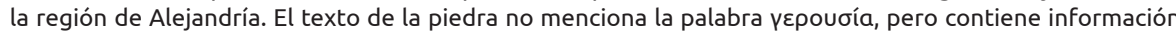
posiblemente conectada con esta institución. Habría sido erigida en honor del ciudadano ilustre Lycarion, a quien se le atribuye el título ápxıý́povta ('presidente del consejo de ancianos', l.5), que habría sido un cargo institucional conferido por derecho hereditario a los integrantes de ciertas familias aristocráticas.

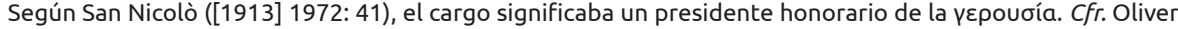
(1941:56-43); Musurillo (1954:108, n.3); El-Abbadi (1964:166, n.2).

48 Cfr. Hrd.1.65; Pl.Lg.692a; D.20.107; Arist.Pol.1270b24; IG22.687.58 (siglo III a.C.). Sobre la vepouoía de Esparta, cfr. Fraser (1972:93-130); Powell ([1988] 2001:29, n.52; 226); Kennell (1995: 8; 45); Lévy (2003: 204; 205).

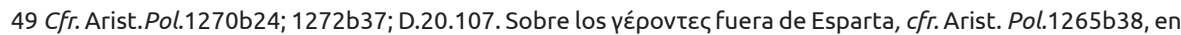
Élide; 1306a17, en Dorileo; OGI 479.11 (siglo II d.C.). 
existió más que una $\gamma \varepsilon \varrho o v \sigma i ́ \alpha . .^{50}$ Reconoció además que las noticias dadas a conocer por el documento permiten corroborar que el consejo era una asociación pública con intervención en los asuntos oficiales de la comunidad. Taubenschlag (1955:576-577, n.16), por su parte, llega a una tesis similar. En su estudio de los papiros egipcios que contienen evidencias sobre la $\gamma \varepsilon$ eovoí $\alpha$ y que están fechados entre los siglos IV a.C. y I a.C., concluyó que en la época ptolemaica no funcionó otro consejo de ancianos distinto del residente en Alejandría. Este argumento fue respaldado por Momigliano (1944:115) y El-Abbadi (1964:164, 166), quienes aseguran que los alejandrinos tuvieron solo un consejo de ancianos en el último período ptolemaico, y por Gambetti (2009:162-163), quien va más allá en su interpretación y estima que la $\gamma \varepsilon \emptyset o v \sigma i ́ \alpha$ ya habría existido desde el inicio del gobierno de los Ptolomeos. ${ }^{51}$ Y si bien no hay acuerdo sobre la naturaleza y función de ese consejo, ${ }^{52}$ los datos registrados en SEG 34.1532 parecen sugerir, como propone San Nicolò (1972:40-42), que fue una institución oficial, cuyos representantes

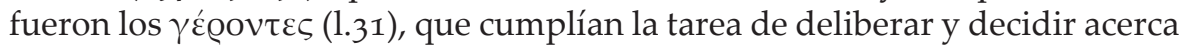
de cuestiones de interés público, con potestad para intervenir en diversos campos de la vida comunitaria. Como funcionarios de la $\gamma \varepsilon \emptyset o v \sigma i ́ \alpha$ tenían el poder ejecutivo de conceder o hacer votar la erección de una piedra (1.4) y de fijar los plazos legales (11.9-10), prescribir decretos (1.31) y autorizar su

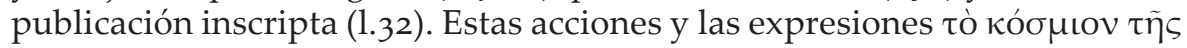

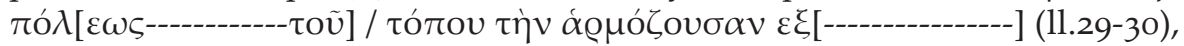

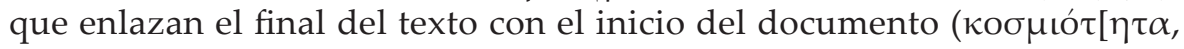
1.4), parecen señalar la actividad jurídica de la $\gamma \varepsilon \varrho o v \sigma i ́ \alpha(1.5)$ y su autoridad sobre los asuntos administrativos de la ciudad. Pese a que seguramente no mantuvieron el poder concedido por los reyes espartanos a los ancianos de su comunidad, la inscripción demuestra que la $\gamma \varepsilon$ govó́ $\alpha$ era un consejo que todavía tenía autoridad para asesorar o tomar decisiones sobre los asuntos vinculados con instituciones oficiales como el gimnasio. Esta tesis podría ser demostrada a partir del vocabulario registrado en la parte intermedia de la inscripción, que será examinada a continuación.

\section{El gimnasio de la ciudad}

La segunda parte del documento contiene el vocabulario que permitiría conocer el posible motivo de la inscripción. Parece registrar la actividad jurídica de la $\gamma \varepsilon @ o v \sigma i ́ \alpha$ ligada con la $\gamma v \mu \nu \alpha \sigma \iota \alpha \varrho \chi i ́ \alpha$ y con el ingreso de los menores de edad en el gimnasio de la ciudad, como se desprende de las 11.10-20 que anotamos abajo:

50 El resto de la documentación que registra el nombre yepouбía en Egipto es papirológica y se ubica en Oxirrinco (Bahnasa), en el siglo III d.C. Cfr. P.Oxy. 43.3101.3; P.Ryl.Gr. 4.599. 12; SB 8.9901.22.

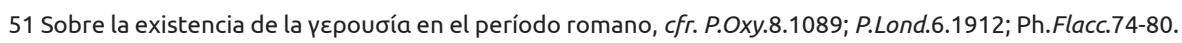

52 El-Abbadi (1964:164) afirma que la crítica está dividida en dos visiones principales. Una defiende que la asociación fue una institución pública relacionada con asuntos de índole religiosa, y otra que participó de la

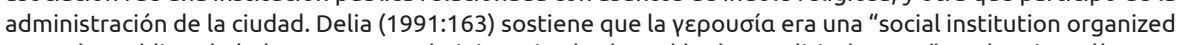
around a public cult (...) was not an administrative body and had no political status". En la misma línea se posiciona Gambetti (2009:57-58), quien sugiere que, en el siglo I d.C., las funciones de la institución muy probablemente se limitaron a deberes representativos y religiosos. Bowman; Rathbone (1992:115-118), en cambio, también atribuyen al consejo deberes administrativos y políticos. 


\begin{tabular}{|c|c|c|}
\hline 10 & 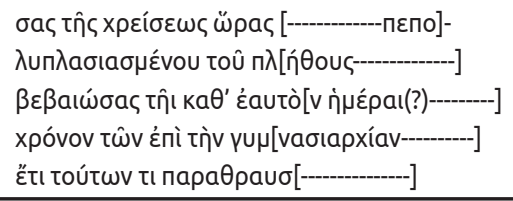 & $\begin{array}{l}\text { al tiempo necesario ... } \\
\text { cuando incrementa el número ... } \\
\text { en el plazo establecido ... } \\
\text { el tiempo conforme a la gimnasiarquía... } \\
\text { aun [si] algo de esto se infringe ¿? ... }\end{array}$ \\
\hline 15 & 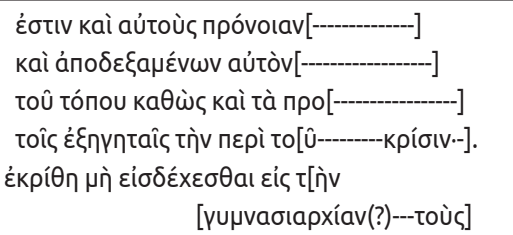 & $\begin{array}{l}\text { los mismos que también tienen el propósito ... } \\
\text { y aprobándolo ... } \\
\text { de allí mismo según... la sentencia sobre ... por } \\
\text { [los exégetas- } \\
\text { Ha decidido no aceptar en la gimnasiarquía(¿?) ... } \\
\text { [a los }\end{array}$ \\
\hline 20 & 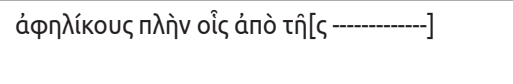 & $\begin{array}{r}\text { menores [ante la ley] excepto aquellos para } \\
\text { [quienes... }\end{array}$ \\
\hline
\end{tabular}

Las líneas conservan la información que mayor dificultad entraña al momento de su interpretación. Registran el tiempo establecido para que se decida

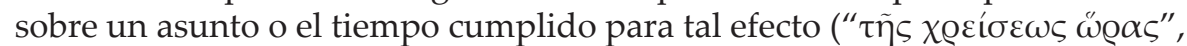

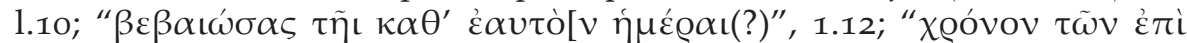

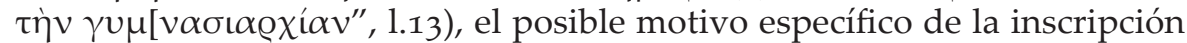

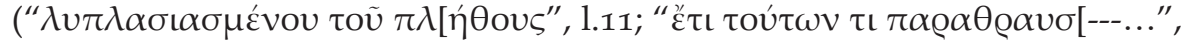
1. 13), el cargo público o magistratura involucrada en tal motivo, que el documento nombra al menos dos veces por medio del término $\gamma u \mu v \alpha \sigma \iota \alpha \varrho \chi i ́ \alpha$ (1l.13, 19); también mencionan la disposición jurídica o resolución emitida

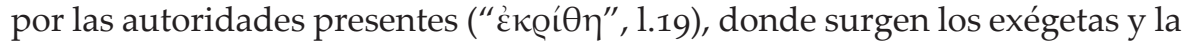
sentencia que rechaza la pretensión de una demanda imposible de precisar

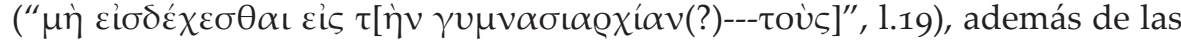
posibles partes o sujetos del proceso resolutivo, que el documento designa con

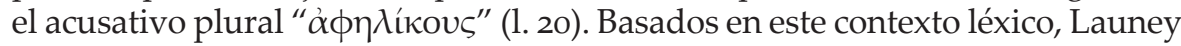
(II 1950:837) y Delorme (1960:137, n.5) señalan que la estela posiblemente hace referencia a un gimnasio; sugieren que es un decreto votado en honor de una persona que, entre otros servicios prestados, parece haber hecho distribuciones de aceites atléticos. ${ }^{53}$ El-Abbadi (1964:164) se ubica en la misma línea; plantea que el texto parece contener un decreto honorífico para distinguir a una persona o grupo de personas de identidad desconocida, mientras que Fraser (1972:177, n.16) no arriesga ninguna temática en particular. Solo expone que el documento alude en gran medida al gimnasio, y que la $\gamma \varepsilon$ Eovorí $\alpha$ en cuestión fue un cuerpo asociado con esa entidad o institución efébica ${ }^{54}$ en lugar de un consejo municipal. En este sentido, el autor razona que si la inscripción es un documento emitido por la $\gamma \varepsilon \varrho o v \sigma i ́ \alpha$, "is a decree of a koเvóv" (1972:177, n.16) y no de la $\gamma \varepsilon \varrho o v \sigma i ́ \alpha$ cívica. ${ }^{55}$ Bingen (1984:241), por su parte, adopta una posición intermedia. Si bien afirma que el documento podría tratarse de

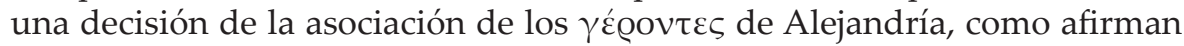
Meyer y Fraser, o de un decreto votado en honor de una persona que proporcionó aceites atléticos, como señalan Launey y Delorme, considera que hay poco apoyo léxico para la tesis que defiende que el texto es sólo un decreto honorífico (El-Abaddi), por más que algunos detalles de la primera parte del documento puedan interpretarse a modo de elogio del comportamiento de una persona con un cargo oficial. Bingen (1984:241), en cambio, piensa que el documento podría referir a la votación de un decreto por una $\gamma \varepsilon \varrho o v \sigma i ́ \alpha$ o un

53 Sobre el uso de aceites en el gimnasio y los baños, cfr. IG 12(9).236.21 (Eretria, siglo II/I a.C.); P.Teb.117.61 (siglo I a.C.); IG 4.597.13; 606.8 (Argos).

54 Cfr. Poland (1909:98-102); Fraser (1972:177, n.16).

55 Cfr. San Nicolò ([1913] 1972:41); Musurillo (1954:108, n.3). 


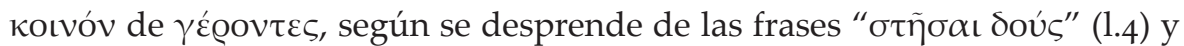

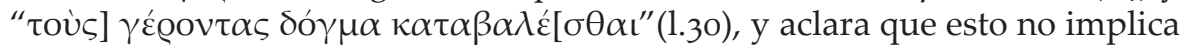
que el documento sea un decreto, sino simplemente que se somete a votación un asunto de interés estatal presumiblemente relacionado con el gimnasio.

Esta última interpretación parece estar avalada por otros datos registrados por la inscripción, en especial aquellos anotados entre las 11.19-21, que presentan una peculiaridad gráfica en la l.19 no considerada por Milne (Strack) y Breccia, pero sí advertida por Bingen (1984:242):

\begin{tabular}{|c|c|c|}
\hline 19 & 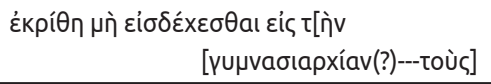 & $\begin{array}{r}\text { Ha decidido no aceptar en la gimnasiarquía(¿?) ... } \\
\text { [a los }\end{array}$ \\
\hline 20 & 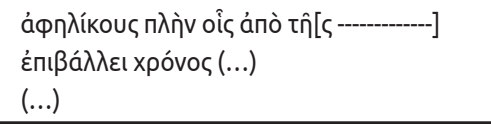 & $\begin{array}{l}\text { menores [ante la ley] excepto aquellos para } \\
\text { [quienes... } \\
\text { impone una edad... (...) }\end{array}$ \\
\hline 28 & 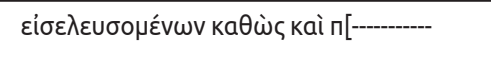 & $\begin{array}{l}\text { a los que/de las que entrarán/ingresarán al } \\
\text { [mismo tiempo que ... }\end{array}$ \\
\hline
\end{tabular}

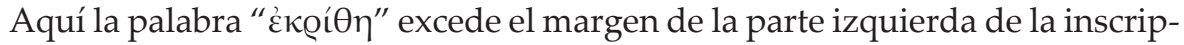
ción. Semejante hallazgo llevó a Bingen a sugerir que una nueva sección del

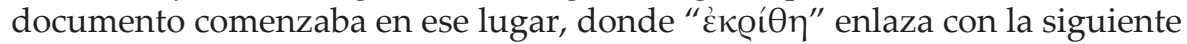

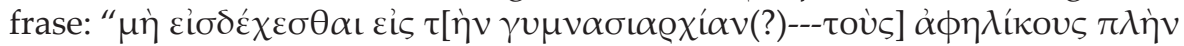

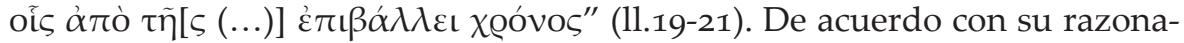

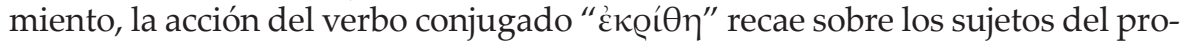
ceso resolutivo a los que el texto refiere con el término " $\alpha \phi \eta \lambda$ íkous" (1.20), que es un concepto clave para el entendimiento de la epigrafía completa. De hecho, $S E G 34.1532$ es una de las primeras fuentes ${ }^{56}$ que documenta la forma con tema vocálico $\alpha \dot{\alpha} \phi \hat{\lambda} \iota \kappa o \varsigma^{57}$ en un contexto léxico de tipo legal ${ }^{58}$ y en conexión con la

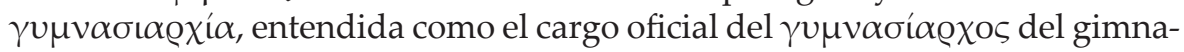
sio. Esta institución, destinada a la formación intelectual y entrenamiento físico, educaba a los individuos que todavía no habían alcanzado la adolescencia o juventud, por lo que no es equivocado pensar que la piedra identifique a este grupo etario con el acusativo plural del nominativo $\alpha \dot{\phi} \eta \dot{\lambda} \iota \kappa \circ \varsigma$, cuya aparición

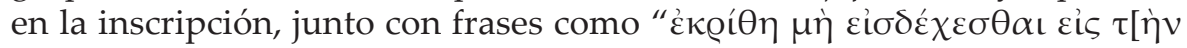

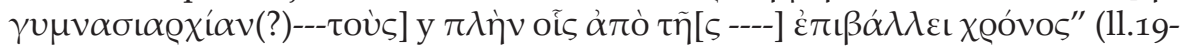
21), cambian el rumbo de las interpretaciones formuladas antes de Bingen. Lejos de la tesis que caracteriza al documento como un decreto honorífico, las 11.19-21 podrían referir a los menores de edad que son dejados fuera de

56 Otra inscripción, conocida como IGLA 162.20, también registra la misma forma en un contexto similar.

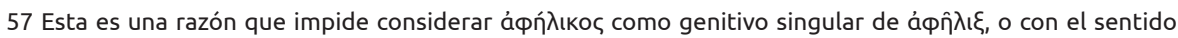

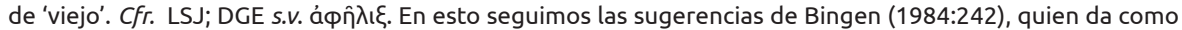

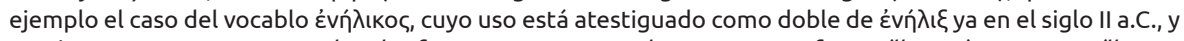
precisamente en un contexto legal. Cfr. P.Dryton 33; P.Lond. III 612; P.Grenf. 1.17 (II. 1-27); SB 1.4638 (II. 1-27

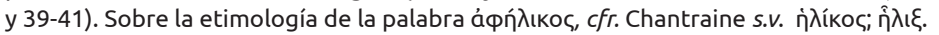

$58 \mathrm{El}$ resto de los testimonios pertenecen a papiros y se ubican después del siglo I d.C. Su uso en una fór-

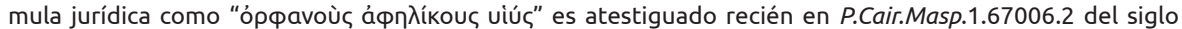
VI d.C., que contiene una petición que una viuda de nombre María, residente del pueblo de Sabbis en el nomos Theodosiopolite, realiza al dux de Thebaid, probablemente Fl. Marianos. La palabra también surge en P.Oxy.17. 2134. 31 y 45 (año 170 d.C.), en el contexto del registro de una escritura de hipoteca o de un testamento que es problemático. Pero probablemente pueda ser certificada en P.Oxy.2.351 = SB 12.10795 del año 28 d.C. Para el estudio de otros papiros que registran una forma similar, $c f$. P.Soterichos26.5 (año 82-96

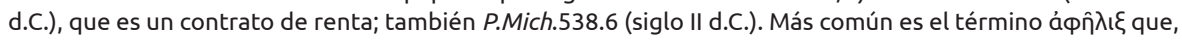
en sentido jurídico, también refiere al 'menor de edad', pero su aparición es frecuente en papiros de época tardía. Sobre su uso en documentación ubicada en Egipto, cf. P.Wisc. 2 46, 35 (siglo I a.C.); P.Ryl.Gr.2.118, 14 (siglo I a.C., Arsinoites, Fayum); BGU4.1121.6 (siglo I a.C., Alejandría); también P.Mich.577.3.11 (siglo I d.C.); P.Oxy. 3471.13 (siglo II d.C.); P.Grenf.1.49.12 siglo (III d.C.). 
un grupo o dignidad, 59 a excepción de los incluidos en la expresión "oĩ $\alpha$ àंò $\tau \tilde{\eta}[\varsigma----] "$ que, al parecer, cumplen ciertos requisitos que el documento tal vez menciona pero que su estado de conservación impide conocer. Aunque también se podría reflexionar que el texto refiere a los menores que tendrán acceso a

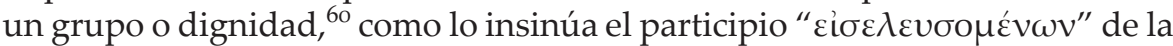
1.28 , que podría aludir a la entrada en un cargo ${ }^{61} \mathrm{o}$ al inicio de una actividad o función determinada en una entidad pública como el gimnasio.

En conexión con lo explicado más arriba, esta institución educativa, de la misma manera que la $\gamma \varepsilon$ oovó́ $\alpha$, no fue nativa de Egipto, sino un establecimiento griego en tierra ptolemaica, como asegura Taubenschlag (1955:638). ${ }^{62}$ El autor explica que, durante el período de los Ptolomeos, esta entidad existía no solo en las $\pi$ $\delta \dot{\lambda} \varepsilon\llcorner\varsigma$ griegas, sino también en las metrópolis y en otros pueblos. Sostiene a su vez que en cada uno de estos lugares, el gimnasio era una institución pública organizada por una empresa privada y encabezada por el

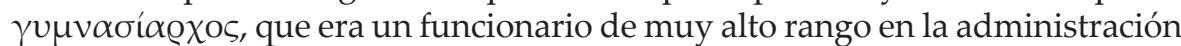
pública y la máxima autoridad del gimnasio. ${ }^{63}$ Como entidad particular, tenía un dueño o propietario, ${ }^{64}$ posiblemente igual al $\gamma v \mu v \alpha \sigma i \alpha \varrho \chi 0 \varsigma$, encargado de todos los gastos relacionados con el mantenimiento del establecimiento, cuyos fondos en ocasiones eran suministrados desde el exterior. ${ }^{65}$ Como institución pública, estaba bajo el control del gobierno oficial y supervisada por la $\gamma \cup \mu v \alpha \sigma \iota \alpha \varrho \chi i ́ \alpha$, de ahí que los asuntos referidos a los casos de ingreso y

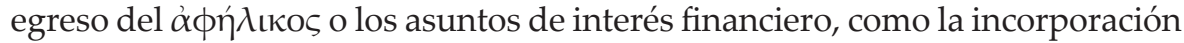
de los menores de edad de familias de nivel económico elevado, fuera motivo de discusión en la esfera jurídica. ${ }^{66}$ Es posible también que el cuerpo facultado para la intervención en esos asuntos fuera la $\gamma \varepsilon \emptyset o v \sigma i ́ \alpha$, según se deduce de SEG 34.1532. Este documento demostraría entonces que el consejo de ancianos todavía estaba vinculado con la organización del gimnasio de la ciudad, y que su actuación legal tenía injerencia sobre las decisiones de admisión de los menores al gimnasio, cuyo ingreso era una condición indispensable para la obtención de la ciudadanía (Taubenschlag 1955:638-640) ${ }^{67}$ y obligatorio para toda la población griega que no superara los trece años de edad y que reuniera los requisitos económicos establecidos normativamente. ${ }^{68}$

59 Cfr. Bingen (1984:242), quien encuentra una apelación a una decisión arbitral en la línea 8, donde la frase

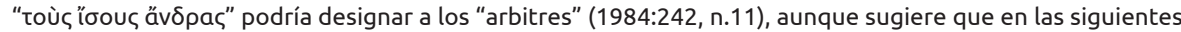
líneas la expresión haría referencia al grupo pequeño de "gymnasiarquables".

60 Cfr. Bingen (1984:242).

61 Esta propuesta se asienta sobre una restitución arbitraria que Bingen (1984:242) propone de las ll.19-20.

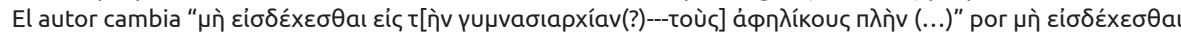

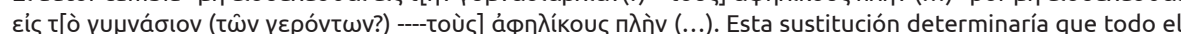
texto se refiera a una magistratura y el lustre o los recursos que aporta a la ciudad el ingreso en el cargo de

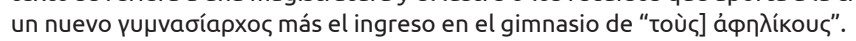

62 Sobre el gimnasio helenístico, cfr. Kah; Scholz (2004).

63 Sobre el yujvacíapxoৎ en Egipto ptolemaico y romano, cfr. BGU 1256.27 (siglo II a.C.); SB 7246.4 (II a.C.); también I.Al12.120.

64 Cfr. SB 7245.

65 Cfr. P.Tebt.3.1.700; Taubenschlag (1955:638).

66 Taubenschlag (1955:638) sostiene que "the gymnasium -although an object of law- was treated as a legal person capable of possessing propriety, like the noגıтвúpata and the associations".

67 Incluso las personas a las que se les otorgaba la ciudadanía eran simultáneamente introducidas en el gimnasio. Cfr. Kortenbeutel (1937:44); Taubenschlag (1955:639).

68 Sobre los requisitos para la admisión y el entrenamiento requerido, cfr. Taubenschlag (1955:640-642). 
Conforme a lo expuesto, no es equivocado aceptar la tesis de Bingen (1984:243), para quien la decisión informada a través de la forma conjugada " $k$ koí $\theta \eta$ " de la l.19 se refiere a las condiciones económicas bajo las cuales ciertos menores de edad se encontrarían en la situación de ser llamados a entrar en el gimnasio dirigido por la $\gamma v \mu v \alpha \sigma \iota \alpha \varrho \chi_{i ́} \alpha .{ }^{69}$ En este sentido, el autor asegura que SEG 34 . 1532 es un testimonio sustancial en la medida que ilustra cómo la mortalidad, incluso en las clases acomodadas, movilizaba una parte importante de las fortunas familiares sobre la cabeza de los menores y llevaba a garantizar el dex $\alpha i ́$ por patrimonios y no por personas. ${ }^{70}$ Esta tesis podría estar avalada por las 11.21-29 que anteceden el final del documento, donde se localiza una serie de valores monetarios ligada, al parecer, con la entrada en una institución dependiente de la $\gamma u \mu v \alpha \sigma \iota \alpha \varrho \chi i ́ \alpha$ :

\begin{tabular}{|c|c|c|}
\hline 21 & 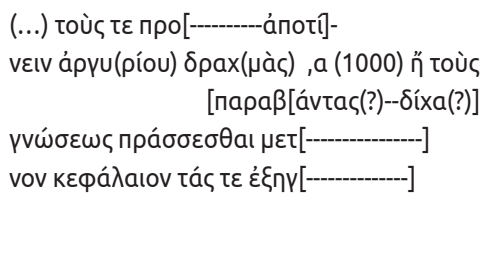 & $\begin{array}{l}\text { menores [ante la ley] excepto aquellos para } \\
\text { [quienes... } \\
\text { impone una edad..., a los... } \\
\text { pagar } 1000 \text { dracmas de plata o a los que se } \\
\quad \text { [apartan de [la ley](¿?)... contra } \\
\text { la instrucción judicial que exige ... } \\
\text {....cabeza / principal a los ... }\end{array}$ \\
\hline 25 & 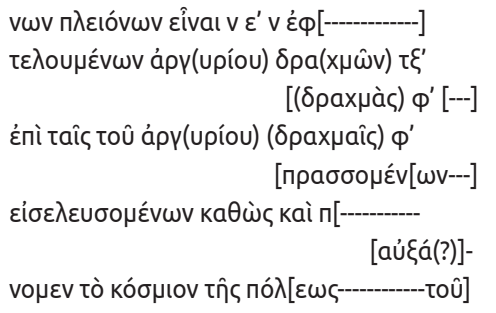 & $\begin{array}{l}\text {...de lo que es superior a cinco... } \\
\text { pagando } 360 \text { dracmas de plata, } 500 \text { dracmas... } \\
\text { exigir sobre } 500 \text { (dracmas) de plata ... } \\
\text { a los que entrarán al mismo tiempo que ... } \\
\text { aumentamos el orden de la ciudad ... }\end{array}$ \\
\hline
\end{tabular}

Al igual que sucedió con los fragmentos analizados más arriba, la mutilación del documento impide obtener un contexto completo de los montos económicos

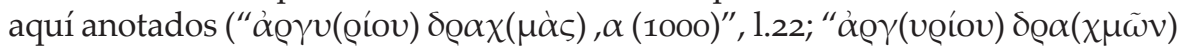

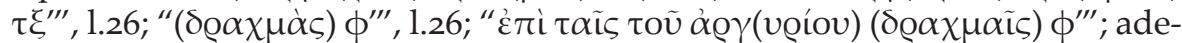
más de " $\varepsilon^{\prime \prime \prime}, 1.25$, de valor incierto), como del propósito de su aplicación; sin embargo, todo el texto parece referir a los recursos que aporta a la ciudad el ingreso de los " $\alpha \phi \eta \lambda$ íkous" de la 1.20. Esta conjetura podría estar sustentada

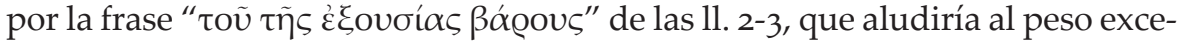
sivo de una carga económica que se enlaza directamente con la $\gamma v \mu v \alpha \sigma \iota \alpha \varrho \chi i ́ \alpha$ y el costo de los gastos del gimnasio. De hecho, como se desconoce si en el período ptolemaico la $\gamma v \mu v \alpha \sigma \iota \alpha \varrho \chi i \alpha$ era una liturgia, ${ }^{71}$ es probable que el propietario del gimnasio no siempre pudiera cubrir el dispendio de las reparaciones, mejoras o mantenimiento general del lugar, y que los montos económicos indicados en la piedra estuvieran vinculados con el financiamiento

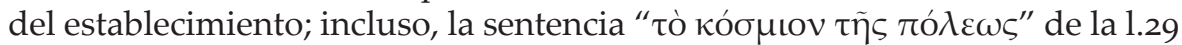

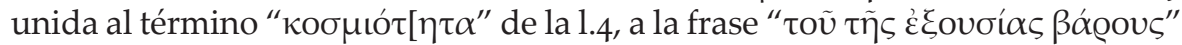

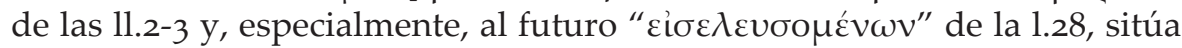
el problema en el nivel de la carga económica y, sobre esta tesis, en el valor monetario exigido, más que en el acceso de un individuo al gimnasio. ${ }^{72}$ Esto

69 Cfr. Bingen (1984:243).

70 Sobre la posible función de los exégetas en este pasaje, cfr. Jouguet (1911:317); Bingen (1984:243, n.16).

71 Cfr. Isoc.16.35; Plu.Nic.3; también D.20.125; X.Ath.1.13; Oec.2.6; IG 12(2).82.23 (Mitilene); Taubenschlag (1955:642).

72 Cfr. Bingen (1984:242); también Pleket; Stroud (1987:419), quienes reproducen las palabras de Bingen. 


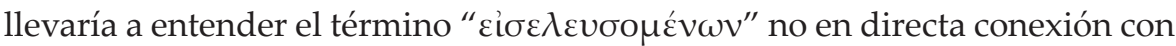
la entrada de los menores en la institución educativa, sino con el ingreso del dinero destinado al gimnasio de la ciudad.

Por lo demás, SEG 34. 1532 carece de otros indicios concluyentes que permitan afirmar las tesis previamente propuestas. La inscripción termina con la orden oficial de publicar la piedra sin más datos que los analizados hasta el momento, y no hay evidencia externa que asista en la tarea de descifrar con mayor grado de certeza la información allí contenida. Esta es la razón por la que no se puede descuidar ni la tesis que propone entender la inscripción como un decreto del cuerpo de ancianos asociado con el gimnasio de la ciudad, ni aquella que busca ir más allá en la interpretación y advierte que el texto refiere al ingreso de los menores de edad al gimnasio o a la decisión oficial sobre la carga económica que los nuevos ingresantes seleccionados a partir de sus patrimonios familiares estaban obligados a aportar a la institución educativa. Cada una de estas interpretaciones no es conclusiva, pero puede ser defendida por el vocabulario conservado en la piedra.

\section{Conclusión}

La única evidencia documental que aporta información léxica sobre la $\gamma \varepsilon \varrho o v \sigma i ́ \alpha$ en Egipto ptolemaico es SGE 34.1532, que registra el término referido al consejo de ancianos de una manera completa y no fragmentaria. Esta referencia y los datos obtenidos por los estudiosos de la piedra a partir del examen de la paleografía de la misma, podría confirmar que esta institución estuvo activa en Alejandría en el siglo II a.C. La ausencia de otros documentos que den noticias sobre su funcionamiento no descarta la existencia histórica de esta institución en la ciudad egipcia, cuya actividad y poder jurídico y administrativo pueden ser deducidos a partir del vocabulario utilizado por el texto grabado en la estela. Si bien SGE 34.1532 se encuentra en un estado de fragmentación que hace imposible demostrar cuál era la potestad exacta atribuida a los miembros del consejo presentes durante la decisión expuesta en la piedra, la tesis que concede a los $\gamma \varepsilon \dot{\varepsilon} 00 \nu \tau \varepsilon \varsigma$ de la $\gamma \varepsilon @ o v \sigma i ́ \alpha$ acciones como someter a votación el levantamiento de una inscripción, establecer y autorizar su publicación y resolver asuntos administrativos de las instituciones del gobierno oficial, no resulta improbable. Por el contrario, en el inicio de la inscripción y en la parte final de la misma surgen las palabras $\gamma \varepsilon \varrho o v \sigma i ́ \alpha$ y $\gamma \varepsilon \dot{\varepsilon} 00 v \tau \varepsilon \varsigma$, cuyo registro ha determinado que la mayoría de los investigadores propongan otorgar las acciones antes nombradas al consejo de ancianos; este habría funcionado como un órgano administrativo del gobierno ptolemaico en el siglo II a.C., e intervenido posiblemente en los asuntos relativos a la organización del gimnasio de la ciudad, como lo sugiere la terminología vinculada con esa entidad. El empleo de la palabra $\gamma \varepsilon$ Qovorí $\alpha$ en conjun-

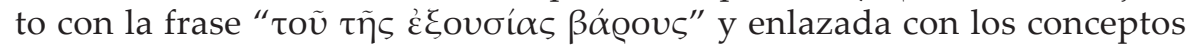
$\gamma \cup \mu v \alpha \sigma \iota \alpha \varrho \chi i ́ \alpha$ y $\alpha \phi \eta ́ \lambda \iota \kappa o \varsigma$, además de los montos económicos expresados en dracmas, podría aludir a los gastos del gimnasio y su financiamiento a través de las cargas patrimoniales de los nuevos menores de edad en condiciones de iniciar su educación en esa institución. Esta interpretación parece estar avalada por el resto del entramado léxico de la estela y justificada por los distintos significados atribuidos a los vocablos que registra, cuya polisemia y el estado deteriorado de la inscripción deja abierta toda tarea de precisar el contenido específico del texto. 
SGE 34.1532 es, por lo tanto, un documento epigráfico con gran resonancia en los estudios históricos sobre las instituciones que estuvieron activas durante el gobierno de los Ptolomeos; pese a que las lagunas y la incertidumbre acerca de su origen y época de publicación no permiten confirmar los datos de emisión de la piedra, el texto allí grabado ayuda a presumir al menos cuáles fueron

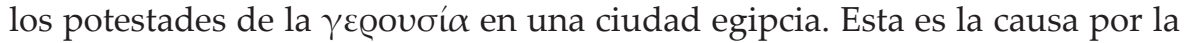
que no se puede descartar el valor histórico de la inscripción que registra las palabras $\gamma \varepsilon \varrho 0 v \sigma i ́ \alpha$ y $\gamma \varepsilon$ É ov $\tau \varepsilon \varsigma$ y su posible función en la época ptolemaica, más aún cuando esa piedra conserva un entramado léxico que posibilitaría conocer que esa entidad constituyó un cuerpo oficial de la administración pública asociado con el gimnasio y su organización. Si bien esta prueba no es definitiva, tal vez resulte suficiente para demostrar que SGE 34.1532 es una de las únicas fuentes que permiten postular que la $\gamma \varepsilon \varrho o v \sigma i ́ \alpha$ funcionó en Egipto ptolemaico en el siglo II a.C. 


\section{Q Bibliografía}

\section{Ediciones}

» Milne, M. L Strack (1906). "Besprechungen und Mitteilungen", Archiv für Papyrusforschung und verwandte Gebiete III, 138.

" Breccia, E. (1911). Catalogue général des Antiquités égyptiennes du Musée d'Alexandrie, Nos 1-568. Iscrizioni greche e latine. Le Caire: L'Institut Francais d'Archéologie Orientale.

»Bingen, J. (1984). "Le Document Gymnasial Breccia 162". En: MNHMH G. A. Petropoulus I. Athens, 239-243.

» Botti, G. (1894). Rivista Egiziana VI.

»Pleket, H. W.; Stroud, R. S. (eds.) (1987). Supplementum Epigraphicum Graecum. Amsterdam: J. C. Gieben.

\section{Bibliografía citada}

" Bowman, A. K. y Rathbone, D. (1992). "Cities and Administration in Roman Egypt", JRS 82, 107-127.

»Delia, D. (1991). Alexandrian Citizenship during the Roman Principate. Atlanta, GA: Scholars Press.

" Delorme, J. (1960). Gymnasion. Étude sur les monuments consacrés à l'éducation en Grèce (des origines à l'Empire romain). Paris: E. de Boccard.

" El-Abbadi, M. A. H. (1964). "The Gerousia in Roman Egypt", The Journal of Egyptian Archaeology 50, 164-169.

》Fraser, P. M. (1972). Ptolemaic Alexandria. 2 vols. Oxford: Clarendon Press.

" Gambetti, S. (2009). The Alexandrian Riots of 38 C.E. and the Persecution of the Jews: A Historical Reconstruction. Leiden-Boston: Brill.

» Jouguet, P. (1911). La Vie Municipale dans l'Égypte Romaine. Paris: Fonternoing et Cie.

» Kah, D., Scholz, P. (eds.) (2004). Das hellenistische Gymnasion. Berlin: Akademie Verlag.

» Kennell, N. M. (1995). The Gymnasium of Virtue: Education \& Culture in Ancient Sparta. Chapel Hill - London: The University of North Carolina Press.

» Kortenbeutel, H. (1937). "Гunváoıov und Bou入ń. Eine Ptolemäische inschrift", Archiv für Papyrusforschung und verwandte Gebiete XII, 44-53.

»Launey, M. (1949-1950). Recherches sur les armées hellénistiques, 2 vols. Paris: E. de Boccard.

» Lévy, E. (2003). Sparte: histoire politique et sociale jusqu'à la conquête romaine. Paris: Seuil. 
" Momigliano, A. (1944). "Review. The Cambridge Ancient History. Edited by S. A. Cook, F. E. Adcock, M. P. Charlesworth. Vol. X. The Augustan Empire, 44 B.C.-A.D. 70. Cambridge: at the University Press, 1934", JRS 34, 109-116.

» Musurillo, H. A. (1954). The Acts of the Pagan Martyrs. (Acta Alexandrinorum). London: Oxford University Press.

»Oliver, J. (1941). The Sacred Gerusia. The American Excavations in the Athenian Agora Hesperia. Supplement VI. Baltimore: American School of Classical Studies at Athens.

» Poland, F. (1909). Geschichte des griechischen Vereinswesens. Leipzig: Druck und Verlag von B. G. Teubner.

» Powell, A. ([11988] 2001). Athens and Sparta. Constructing Greek Political and Social History from 478 BC. London - New York: Routledge.

»San Nicoló, M. (1913). Ägyptischen Vereinwesen zur Zeit der Ptolemäer und Römer. München: Beck.

» Taubenschlag, R. (1955). The Law of Greco-Roman Egypt in the Light of the Papyri (332 B.C.-640 A.D.). Warszawa: Panstwowe Wydawnictwo Naukowe.

\section{Léxicos}

»Chantraine, P. (1968). Dictionnaire étymologique de la langue grecque. Histoire des mots. Paris: Klincksieck.

»Adrados, F. R. (dir.) (DGE) (1980-2009). Diccionario Griego-Español. 7 vols. Madrid: Instituto de Filología.

» Liddell, H.; Scott, R.; Jones, H. (LSJ) (1940). A Greek-English Lexicon. Oxford: Clarendon Press.

» Yarza, F. (1945). Diccionario griego-español. Barcelona: Sopena 
